\title{
Research of Explode Exposure at the Relief Vent System Structures with Soft Transparent Material
}

\author{
Serhii Pozdieiev $^{1 *}$, Yuriy Pidgoretskiy ${ }^{1}$, Olga Nekora $^{1}$, Stanislav Sidnei $^{1}$, \\ Oleksandr Tyshchenko ${ }^{1}$ \\ ${ }^{1}$ Cherkasy Institute of Fire Safety named after Chernobyl Heroes of National university of civil protection of Ukraine \\ *Corresponding authorE-mail: svp_chipbbk@ukr.net
}

\begin{abstract}
A methodology was developed for studying the influence of structural parameters of the relief panels of flexible fencing elements on their behavior in case of explosion. A mathematical model was substantiated on the influence of structural parameters of relief panels with flexible fencing elements on the conditions of their triggering, based on the theory of plates and shells. There was also developed a method for determining the structural parameters for the successful triggering of the relief panels with flexible elements of fencing in case of excessive pressure of explosion, exceeding the maximum allowed parameters.
\end{abstract}

Keywords: dangerous excessive pressure; explosion; fencing flexible elements; relief panels.

\section{Introduction}

Premises of categories A and B should be equipped with external relief panels (RP), according to the Ukraine's norms on explosion and fire safety in accordance with the National Standardization System acting in Ukraine B B.1.1-36: 2016 [1]. At the same time the document indicates that the required RP area should be determined by calculations. The use of flexible fencing elements installed in standard window profiles made of polyvinyl chloride is promising for the construction of the relief panels, since they can be used repeatedly after the removal from frames caused by an explosion. When applying the design of relief panels, it is necessary to study the basic patterns of their behavior in case of explosion, and determine the conditions for the release of the edges of flexible elements from the frames locks of the standard window profile.

Taking into account the lack of standard calculation methods for determining the structure parameters of traditional materials and RP structure systems, a modern approach was used to develop the methodology. This allowed to create a system of mathematical models based on the theory of elasticity of plates and shells. Given the complexity and heterogeneity of the structure of the flexible fencing elements, to describe their mechanical properties, there was used a simplified approach, based on the application of the effective elastic-structural properties of the material, the sheet was made of. The effective elastic-structural properties can be determined by an experimental research and further mathematical interpretation of its measurement results obtained during the experiment.

On the basis of the set of the used mathematical models and the obtained elastic-structural properties, there should be plot nomograms to obtain the structural properties of the RP systems on the basis of the flexible fencing elements installed in PVC frame of a standard window profile. Taking into account the indicated features, there was created and properly tested a methodology based on the application of the calculation method for determining the structural parameters of the RP systems, using a flexible fencing installed in the framework of a standard window profile, according to the regulatory documents acting in Ukraine. The developed methodology is consistent with the relevant methodological and regulatory norms, acting in Ukraine. It is also consistent with the research results conducted by domestic and foreign authors [1-11], which have been tested, discussed and recognized by the academic community and are a part of the main database for literary references and citations by specialists in the sphere.

The entire set of the data, included in this article, is aimed at achieving an important technical result, i.e., providing explosion and fire safety for industrial buildings, where flammable explosive and fire hazardous substances are used. To achieve the aim, there was created a mathematical device for designing the engineering calculations of the RP systems with flexible fencing.

\section{Literature Review}

The analysis of scientific papers has revealed that the provision of fire and explosion safety for industrial buildings with appropriate technological processes is quite important and requires effective and constructive design solutions [2-7]. On implementing technical solutions aimed at protecting the buildings from explosion, there exists a methodology of the blast-resistance evaluation as to the internal deflagrational explosions of gas-air mixture [1]. There is a quite effective method of designing relief panels, referred in the Technical Code of Practice acting in the Republic of Belarus (TCP 45-2.02-38-2006 (02,250) [8]. There are also foreign standards, valid in this sphere, for example, the US Standard NFPA 68 [9] British standard BSEN 14491: 2012 [10]. Furthermore, there are a number of books, papers, theses [11] etc., which consider the issues of protection explosionhazardous industrial buildings with the use of safety relief structures. 


\section{Purpose, Objectives and Results}

The purpose of this article is to develop a mathematical description of the behavior of a RP flexible element in case of explosion. To achieve this purpose, the following tasks should be solved:

- to formulate the basic hypotheses concerning the behavior of a RP flexible element on explosion;

- to develop calculation models of the RP flexible elements;

- to set down the basic mathematical equations and create a methodology for determining the basic constructive parameters of the relief panel with flexible elements.

\section{Technical Description of the Researched Object}

The researched design of the RP systems is based on the ordinary window profile, which is used for glazing the premises of one of the manufacturers. Instead of double-glass units for flexible fencing, there were used standard polycarbonate sheets.

In this case, the indicated sheets are set into a frame of polyvinyl chloride profile TM WDS 400.

Fig. 1 shows the view of a frame made of a standard window profile with an installed polycarbonate sheet.

The structure of transparent fencing is used with expectation that on the RP system triggering, a flexible element of the fencing comes out of the attachment fittings of the frame, reducing the dangerous excessive pressure. In this case, there occurs no destruction of flexible fencing elements; therefore, they can be reused. According to the authors, this may reduce the material and labor costs for the restoration of RP systems.

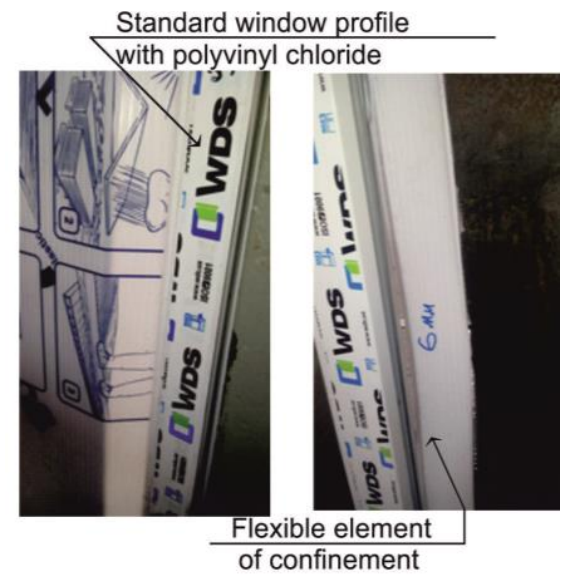

Fig. 1: The view of the glazing element of the researched relief panels (RP) system.

The flexible elements of RP fencing can be produced out of high quality polycarbonate granules, by means of their thermal extrusion. On creating RP systems for the fencing flexible element, it is suggested to use polycarbonate sheets of different thicknesses: $4 \mathrm{~mm}, 6 \mathrm{~mm}$ and $8 \mathrm{~mm}$, as shown in the fig. 2

The fig. 2 also shows the arrangement of cells in polycarbonate sheets of flexible fencing of the researched RP systems.

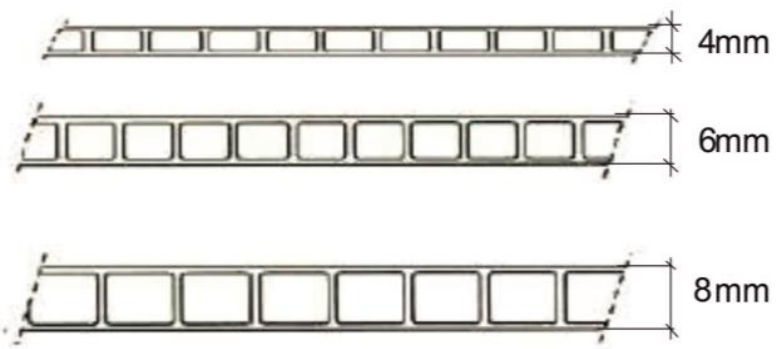

Fig. 2: The structure of sheets of fencing flexible elements used for building the relief panels (RP) systems.

Fig 3. shows the flexible element of RP fencing in section.

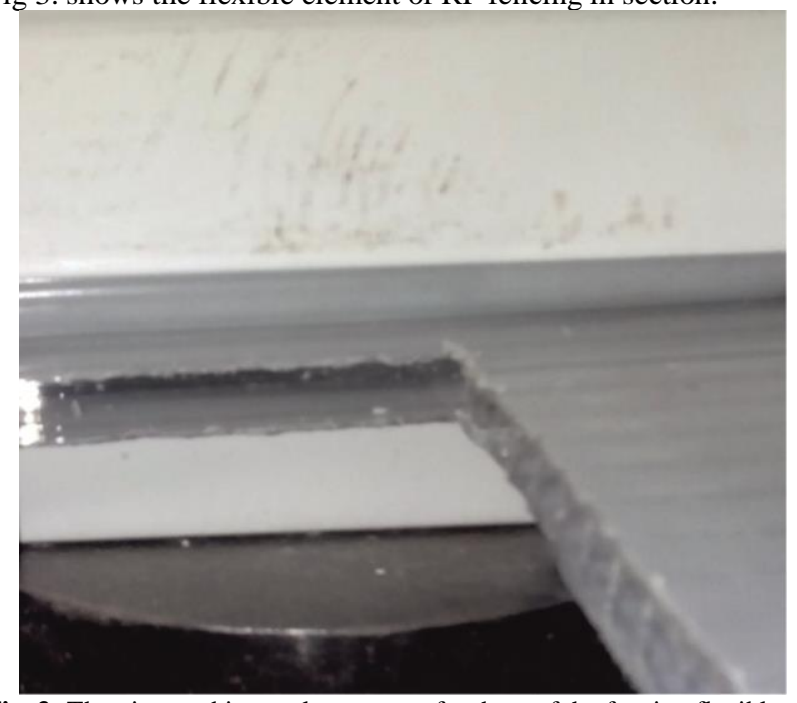

Fig. 3: The view and internal structure of a sheet of the fencing flexible element.

Flexible elements of the fencing are fixed in frames, forming a specific attachment fitting unit. They are fixed in the fitting unit by friction forces. Fig. 4 shows the structure of the fitting unit.

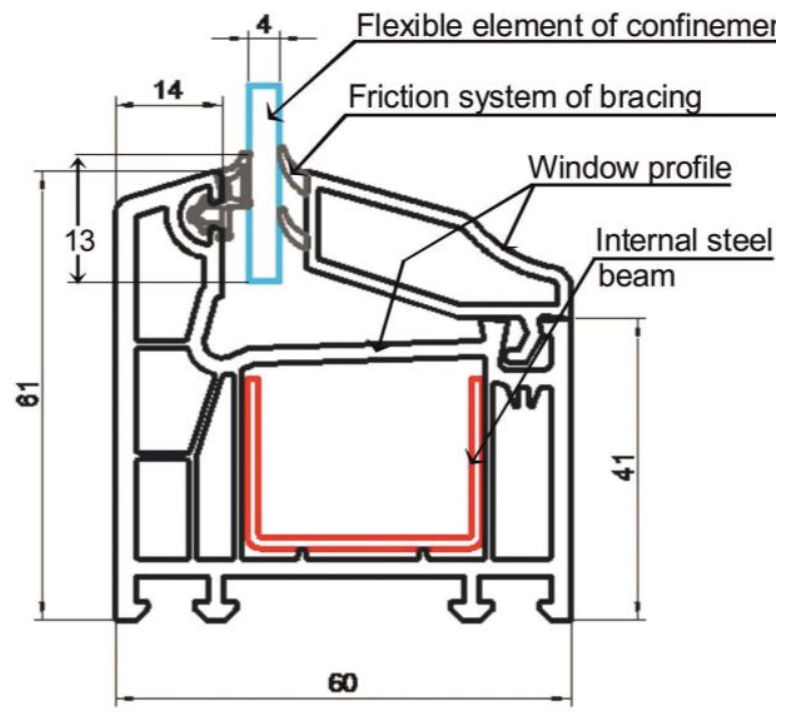

Fig. 4: Structural scheme of the attachment fitting of the fencing flexible elements in a frame of a window profile.

The mount system of attaching RP flexible elements into a frame of the window profile is not rigid. This lets the ends of the sheet, fixed in the frame, to turn. If the sheet is deflected, its end begins 
to move. When applied a certain force, it comes out of the attachment fitting. This allows the frame to be released, creating a vacant space, through which the gas can flow, rapidly reducing the excessive pressure to zero.

Therefore, the structure system can be used as a RP element. A designed size of the opening with a polycarbonate sheet determines the level of excessive pressure that allows the release of the opening, that is, the way of its triggering as a RP element. A system consisting of the required number of such openings is considered a RP system.

The selection of the structure parameters of the composite openings of the RP system in this structure is the basis for the methodology for its calculation. The calculation is possible provided the available reference data, referring the mechanical properties of the material, the sheet is made of, as well as the data on the forces acting on the attachment fittings. Currently, the information is not available; therefore, its definition becomes one of the tasks for creating this methodology.

\section{Basic Theoretical Provisions for the Calculation}

On the solution of the problem with analyzing the force interaction in a RP element consisting of a flexible element (FE) and the assigned window profile, there were formulated the main assumptions and hypotheses regarding this system. Their main provisions are as follows.

1. In case of force impact on the RP elements, made on the basis of FE in the window profile of this construction, there occur only elastic deformations.

2. FE material is homogeneous and isotropic; it is characterized by effective mechanical properties.

3. The frictional force between the draught-strip of the attachment fitting and the FE surface is constant and independent of the velocity of the FE surface and its deformation.

4. While analyzing the force interaction, the FE weight was not taken into account.

5. While analyzing the force issue, all types of loading were considered static, that is, the inertial properties of the material were not taken into account.

6. Transverse deformations of the FE are considered to be far lesser than their overall size. Furthermore, it is considered that they do not influence the results of the deformation data determination in case of a force influence of excessive pressure from an explosion.

7. In case of FE deformation it is considered that it is subjected to pure bending without additional longitudinal deformations of extension or compression.

8. The criterion for triggering the RP element is the displacements of the FE edges in the direction of the smallest size of the opening.

\section{Calculation Models}

For analyzing the force interaction inside a RP element, consisting of FE RP and assigned window profile, there was compiled a calculation model as shown in the Fig. 5.

When considering FE, fixedly attached to frames of the window profile, it is considered as a rectangular plate, which is fixed hingedly with a possibility of free movement of the FE edges longitudinally, while the load is distributed uniformly.

The Fig. 6 shows the calculated application of the load to FE While analyzing the deformation response of the mechanical system (which is the FE, fixedly attached to a frame of the window profile), there should be taken into account the frictional force that holds the FE edges in the attachment fittings.

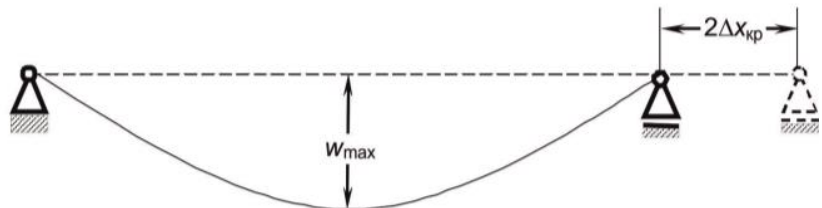

Fig. 5: Calculation model for deformation of a flexible element in a window profile frame designed to determine the critical displacement of its edge.

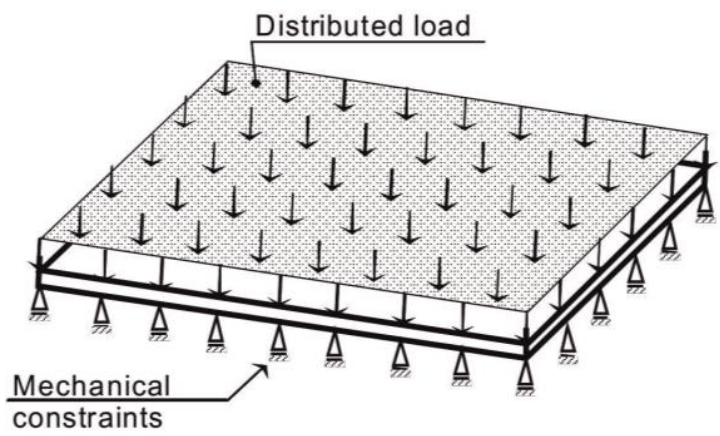

Fig. 6: A model for calculating the force interaction in a flexible element fixedly attached to a frame from a window profile under excess pressure of the explosion.

There should be applied calculation model, shown in the fig. 7 The calculation models should be used for creating a mathematical model that allows obtaining the geometric dimensions of the frame for their future use in RP systems.

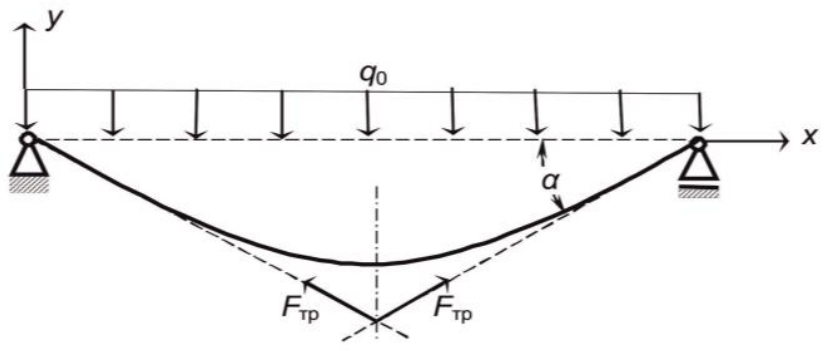

Fig. 7: A model for calculating the force interaction in a flexible element fixedly attached to a frame of a window profile in case of excess pressure of the explosion.

\section{Mathematical Model of Behavior of Flexible Elements in Case of Explosion}

The basis of the developed methodology is the system of mathematical models known from the elasticity theory of plates and shells provided by the works by $\mathrm{S}$. Tymoshenko and his students [12].

With the help of the calculation model of RP elements, the following static equilibrium equation was made:

$\sum Y_{i}=q_{0} \cdot a \cdot b-2\left(F_{m p}^{x} \sin \alpha+F_{m p}^{z} \sin \beta\right)-Q_{y}=0$,

where $q_{0}$ - excess pressure of the explosion, $\mathrm{Pa}$; $a$-the smallest overall size of the opening of the frame, m; 
$b$ - the largest overall size of the opening of the frame, $\mathrm{m}$;

$F_{m p}^{x}, F_{m p}^{q}$ - frictional forces that hold the FE edges inside the attachment fitting along the axis $\mathrm{x}$ and $\mathrm{z}$, respectively, $\mathrm{H}$;

$\alpha, \beta$ - angles of inclination of the tangent to the elastic bending line according to the largest and the smallest sides of the frame opening of the element of the RP system, rad;

$Q_{y}$ - the transverse force at the point of intersection of the diagonals of the opening of the frame section of the RP system, H. The sinuses of the inclination angles of the tangential to the elastic bending line according to the largest and the smallest sides of the frame opening of the RP system element are defined as follows:

$$
\sin \alpha=\frac{\pi w_{\max }}{\sqrt{a^{2}+\pi^{2} w_{\max }^{2}}}, \sin \beta=\frac{\pi w_{\max }}{\sqrt{b^{2}+\pi^{2} w_{\max }^{2}}},
$$

The transverse force $Q_{y}$ can be determined by the formula:
$Q_{y}=\frac{w_{\max } \pi^{6} D \cdot a \cdot b}{16}\left[\sum_{m=0}^{\infty} \sum_{n=0}^{\infty} \frac{(-1)^{\frac{(2 m+1)+(2 n+1)}{2}-1}}{(2 m+1)(2 n+1)\left(\frac{(2 m+1)^{2}}{a^{2}}+\frac{(2 n+1)^{2}}{b^{2}}\right)^{2}}\right]^{-1}$,

where $D$-effective rigidity parameter $\mathrm{FE}, \mathrm{Hm}$; $m=1,3,5,7, \ldots ; n=1,3,5,7, \ldots-$ odd integers

Frictional force is determined as follows:

$F_{m p}^{x}=q_{m p} \cdot b ; F_{m p}^{z}=q_{m p} \cdot a$,

where $q_{m p}$ - distributed frictional forces along the length of the attachment fitting in the frame of the RP element, $\mathrm{H} / \mathrm{m}$

Taking into account the formulas (2) - (4), the equation of equilibrium (1) looks as follows:

$q_{0} \cdot a \cdot b-\frac{w_{\max } \pi^{6} D \cdot a \cdot b}{16} \times\left[\sum_{m=0}^{\infty} \sum_{n=0}^{\infty} \frac{(-1)^{\frac{(2 m+1)+(2 n+1)}{2}-1}}{(2 m+1)(2 n+1)\left(\frac{(2 m+1)^{2}}{a^{2}}+\frac{(2 n+1)^{2}}{b^{2}}\right)^{2}}\right]^{-1}-2 q_{m p}\left(\frac{b \pi w_{\max }}{\sqrt{a^{2}+\pi^{2} w_{\max }^{2}}}+\frac{a \pi w_{\max }}{\sqrt{b^{2}+\pi^{2} w_{\max }^{2}}}\right)=0$

The equation (6) can be used to determine the minimum structural parameters ' $a$ ' and ' $b$ ' of the frame openings from the window profile as structural components of the RP system for a precise definition of the excessive pressure caused by an explosion. It can be used provided the known data of effective hardness parameter $\mathrm{D}$ and the frictional force of the draught-strip along the surface of the FE $F_{m p}$. These parameters can be determined as a result of conducting relevant experimental studies.

$a-\int_{0}^{a-2 \Delta x_{k p}} \sqrt{1+\frac{w_{\max } \pi}{\left(a-2 \Delta x_{k p}\right)} \cos ^{2}\left(\frac{\pi x}{\left(a-2 \Delta x_{k p}\right)}\right)} d x=0$.

This equation was written using a well-known expression of the length of the arc [13]. The integral in equation (6) does not have an analytic expression and is reduced to an elliptic Legendre integral of the 2-d type, which can be determined only by tabular method [13]. A more effective way of solving the equation (6) is a method based on the application of the Simpson formula for the approximate evaluation of certain integrals [13]. When applying the Simpson formula, the equation (6) takes the following form:

$a-\frac{a-2 \Delta x_{\kappa p}}{6}\left(2 \sqrt{1+\frac{w_{\max } \pi}{a-2 \Delta x_{k p}}}+4\right)=0$.

With a help of simple algebraic transformations, an expression was written which is valid for an approximate determination of the maximum deflection of FE under conditions of reaching a critical displacement of the attachment fitting edges of the frame from the window profile, which has the following form:

$\Delta x_{\kappa p}=0.25 \sqrt{36 a^{2}+16 a \pi w_{\max }+\pi^{2} w_{\max }^{2}}-1.5 a-0.25 \pi w_{\max }$,

where $\Delta x_{k p}$ - is the critical displacement of the FE edges in the longitudinal direction towards the smallest overall size of the frame opening of the RP element (see Figures 1 and 3).

\section{Conclusion}

The article proposes a method for studying the influence of the FE RP structural parameters on their behavior in conditions of an explosion:

- for the first time there was proposed a model, based on the theory of plates and shells, of power interaction in the FE RP at the moment of their triggering in case of an explosion;

- there was substantiated a mathematical model of the influence of the RP structural parameters, based on FE, on the conditions of their triggering. The model is based on the theory of plates and shells.

- there was developed a method of the structural parameters' determination for the successful triggering of RP, based on FE, at the excessive pressure of the explosion, exceeding the maximum allowed level.

\section{References}

[1] DSTU [National Standardization System of Ukraine] B V.1.1-36: 2016, Vyznachennya categoriy prymischen', budynkiv, ustanovok za vybuhopogegnoyu ta pogegnoyu nebezpekoyu, (2017), 44 p.

[2] Pozdieiev S., Nuianzin O., Sidnei S., Shchipets S., "Computational study of bearing walls fire resistance tests efficiency using different combustion furnaces configurations", MATEC Web of Conferences, Vol.116, art.no.02027,

(2017), http://dx.doi.org/10.1051/MMM.2017.11602027.

[3] Nekora O., Slovynsky V., Pozdieiev S., "The research of bearing capacity of reinforced concrete beam with use combined experimental-computational method", MATEC Web of Conferences, Vol.116, art. No.02024, (2017), http://dx.doi.org/10.1051/MMM.2017.11602024.

[4] Mygalenko K., Nuyanzin V., Zemlianskyi A., Dominik A., Pozdieiev S., "Development of the technique for restricting the propagation of fire in natural peat ecosystems", Eastern-European Journal of Enterprise Technologies, Vol.1, No.10 (91), (2018), pp. 31-37.

[5] Danchenko Y., Andronov V., Teslenko M., Permiakov V., Rybka E., Meleshchenko R., Kosse A., "Study of the free surface energy of epoxy composites using an automated measurement system", Eastern-European Journal of Enterprise Technologies, Vol.1, No12 (91), (2018), pp.9-17.

[6] Pospelov B., Andronov V., Rybka E., Popov V., Romin A., "Experimental study of the fluctuations of gas medium parameters as early signs of fire", Eastern-European Journal of Enterprise Technologies, Vol.1, No.10 (91), (2018), pp.50-55.

[7] Pospelov, B., Rybka, E., Meleshchenko, R., Gornostal, S., Shcherbak, S. "Results of experimental research into correlations 
between hazardous factors of ignition of materials in premises", Eastern-European Journal of Enterprise Technologies, Vol.6, No.10 (90), (2017), pp.50-56, http://dx.doi.org/10.15587/17294061.2017.117789

[8] TCP 45-2.02-38-2006 (02250), Konstrukcii legkosbrasyvaemye. Pravila rasscheta, Minsk, Ministerstvo architectury i stroitelstva Respubliki Belarus, (2006), 27 p.

[9] NFPA 68. Standard on Explosion Protection by Deflagration, Venting, Edition, (2013), 88 p.

[10] BS EN 14491: 2012, Dust Explosion Venting Protective Systems, (2008), $32 \mathrm{p}$

[11] Pilyugin L., Construkcii soorugeniy vzryvoopasnych proizvodstv, Moskva: Stroizdat, (1988), 315 p.

[12] Timoshenko S., Voinovsky-Kryger S., Plastinki $i$ obolochki, Moskva: Nauka, (1966), $636 \mathrm{p}$

[13] Piskunov N., Differencialnoe $i$ integralnoe ischislenie. 13-ya redakcia, Moskva: Nauka, Glavnaya redakcia nauchnoy literatury, (1985), $560 \mathrm{p}$ 